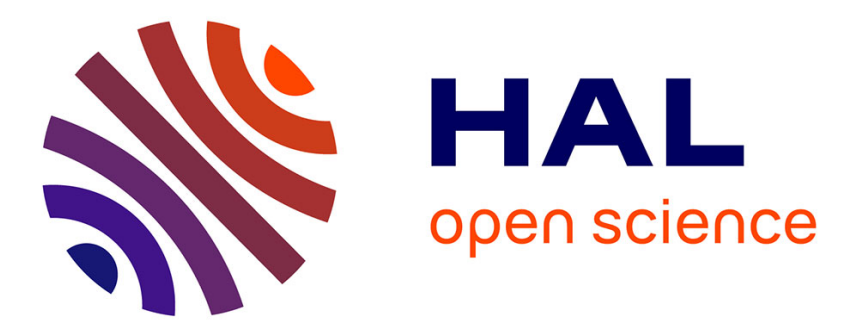

\title{
Cell biology of microbes and pharmacology of antimicrobial drugs explored by Atomic Force Microscopy
}

\author{
Cécile Formosa-Dague, Raphael E Duval, Etienne Dague
}

\section{To cite this version:}

Cécile Formosa-Dague, Raphael E Duval, Etienne Dague. Cell biology of microbes and pharmacology of antimicrobial drugs explored by Atomic Force Microscopy. Seminars in Cell and Developmental Biology, 2018, 73, pp.165 - 176. 10.1016/j.semcdb.2017.06.022 . hal-01907671

\section{HAL Id: hal-01907671 \\ https://hal.laas.fr/hal-01907671}

Submitted on 22 Nov 2018

HAL is a multi-disciplinary open access archive for the deposit and dissemination of scientific research documents, whether they are published or not. The documents may come from teaching and research institutions in France or abroad, or from public or private research centers.
L'archive ouverte pluridisciplinaire HAL, est destinée au dépôt et à la diffusion de documents scientifiques de niveau recherche, publiés ou non, émanant des établissements d'enseignement et de recherche français ou étrangers, des laboratoires publics ou privés. 
Review

\title{
Cell biology of microbes and pharmacology of antimicrobial drugs explored by Atomic Force Microscopy
}

\author{
Cécile Formosa-Dague ${ }^{\text {a, b, c, , , }}$, Raphaël Emmanuel Duval ${ }^{\text {b, c, d }}$, Etienne Dague ${ }^{\text {a, }}$ \\ ${ }^{a}$ LAAS-CNRS, Université de Toulouse, CNRS, Toulouse, France \\ b CNRS, UMR 7565, SRSMC, F-54506 Vandouvre-lès-Nancy, France \\ c Université de Lorraine, UMR 7565, SRSMC, Faculté de Pharmacie, F-54001 Nancy, France \\ d ABC Platform ${ }^{\circledR}$, F-54001 Nancy, France
}

Article history:

Received 23 May 2017

Received in revised form 22 June 2017

Accepted 26 June 2017

Available online $\mathrm{xxx}$

\begin{abstract}
Antimicrobial molecules have been used for more than 50 years now and are the basis of modern medicine No surgery can nowdays be imagined to be performed without antibiotics; dreadful diseases like tuberculosis, leprosis, siphilys, and more broadly all microbial induced diseases, can be cured only through the use of antimicrobial treatments. However, the situation is becoming more and more complex because of the ability of microbes to adapt, develop, acquire, and share mechanisms of resistance to antimicrobial agents. We choose to introduce this review by drawing the panorama of antimicrobial discovery and development, but also of the emergence of microbial resistance. Then we describe how Atomic Force Microscopy (AFM) can be used to provide a better understanding of the mechanisms of action of these drugs at the nanoscale level on microbial interfaces. In this section, we will address these questions: (1) how does drug treatment affect the morphology of single microbes?; (2) do antimicrobial molecules modify the nanomechanical properties of microbes, or do the nanomechanical properties of microbes play a role in antimicrobial activity and efficiency?; and (3) how are the adhesive abilitites of microbes affected by antimicrobial drugs treatment? Finally, in a second part of this review we focus on recent studies aimed at changing the paradigm of the single molecule/cell technology that AFM typically represents. Recent work dealing with the creation of a microbe array which can be explored by AFM will be presented, as these developments constitute the first steps toward transforming AFM into a higher throughput technology. We also discuss papers using AFM as NanoMechnanicalSensors (NEMS), and demonstrate the interest of such approaches in clinical microbiology to detect quickly and with high accuracy microbial resistance.
\end{abstract}

(C) 2017 .

\section{Introduction}

Most pathogenic bacteria and yeasts are part of the human natural flora. But in some cases, these commensal bacteria become pathogenic, particularly in immunocompromised patients. It is to fight these bacteria that antibiotics were developed. An antibiotic is defined as a substance that inhibits the growth or kills microorganisms. After the discovery of the first antibacterial in the early 1900's, the development of antibiotics and antifungals knew, during the 20th century, a golden era, where many different molecules were identified and used massively on patients. This led, unfortunately, to the development of resistance mechanisms by the microbes exposed to these

Corresponding authors at: LAAS-CNRS, Université de Toulouse, CNRS, Toulouse, France.

Email addresses: formosa@insa-toulouse.fr (C. Formosa-Dague); edague@laas.fr (E. Dague)

${ }^{1}$ Present address: LISBP, Université de Toulouse, CNRS UMR 5504, INRA UMR 792, INSA, 135 Avenue de Rangeuil, F-31077 Toulouse, France. molecules. Whereas for decades the screening approaches used to discover new antibiotics were successful, nowadays the discovery rate of new molecules has dropped dramatically. Indeed, since 1987 no new antibiotic class was found. And in the meantime, microbes continued to evolve at the rate of a new generation every $20 \mathrm{~min}$ for some strains, and therefore some have now become resistant to all known antibiotics. We must acknowledge this present situation, which can be summarized by the sentence "bad bugs, no drugs" [2].

In this context, several strategies could help finding a way out of this situation. The increasing number of antimicrobial resistant microorganisms motivates prospective research toward discovery of new antimicrobial substances. Indeed, the need for new antimicrobial agents is high, and if no new agents are discovered, many of the current therapies will no longer work in the future, even for common infections $[3,4]$. But as antimicrobial resistance increases, the race will intensify between microbes and novel drug discovery and development efforts. Moreover, there are controversies concerning the cost-effectiveness of such research. Therefore new strategies have to be developed to overcome pathogen resistance. One of these strategies 
developed for bacteria is the analysis of the bacterial genome, that constitute a way to identify new targets, by looking at the "inside" of the bacteria, i.e. at their chromosomes and plasmids [5]. However, what about the "outside" of bacteria? And what about the yeast cell wall? To combat drug resistance, it is necessary to develop new technologies that allow the study of the cell envelope of bacteria and pathogenic yeasts, since this is where components that are unique and essential for the microorganisms are. In the context of antimicrobial therapies, the cell surface represents also the first interface in interaction with antimicrobial molecules.

In this context, Atomic Force Microscopy (AFM) [6], a technology adapted from physics to the field of microbiology, is particularly well suited to the study of microorganisms as it combines a high-resolution imaging capacity with little sample preparation. In addition, samples can be imaged in fluid environments, which provides possibilities for monitoring live microbes in real-time. Different imaging modes have been developed over time; the principal ones used for imaging of microbes are contact mode and oscillating mode (or dynamic mode). While in contact mode, a sharp tip scans a sample with a force applied maintained constant by adjusting the tip height; in oscillating mode, stiff cantilevers are oscillated close to resonance frequency while scanning across a sample. Although contact mode has been widely used on different bacterial and yeasts species, its application to soft biological samples often requires careful manipulation as the lateral forces exerted by the tip can damage the samples. In oscillating mode, used in its simplest application, it is the change in the oscillation during the scanning that reports on the topography of the sample. Therefore in this mode frictions are in principle, significantly reduced. However in some cases of biological samples imaged under physiological conditions, the electrolytes present in the medium can interact with the tip through low-range surface forces that can affect the vibration of the tip during its trajectory. As a result, the oscillation amplitude can be modified, leading to a deformation of the sample. To circumvent these problems, imaging through force spectroscopy mode was developed. Indeed, AFM is not only an imaging technology; it is also a highly sensitive force machine, able to measure forces as small as $20 \mathrm{pN}$. An AFM is therefore able to record force-distance curves, where the force experienced by the probe is plotted as a function of the probe-sample separation distance. These force curves can then be interpreted through a physical model that provides access to the biophysical properties of the living material, $i$. e. its nanomechanical and nanoadhesive properties [7,8]. But to use force spectroscopy as an imaging mode, a matrix of force curves should be acquired across a sample surface, a process known as force-volume imaging. This mode presents the advantages of avoiding lateral forces and thus damaging of the sample, while simultaneously collecting information on its topography and biophysical properties. Moreover, tips used can be functionalized, either with biomolecules or with single living cells, which opens up the way to study specific molecular interactions at the cellular interface $[9,10]$, or between two different or similar cellular interfaces [11-13]. However, the time needed to record a high-resolution image in this mode does not match the dynamics of biological processes. Therefore advanced multiparametric imaging modes were developed. These modes are based on force curve acquisition but are processed much quicker than classical force-volume, therefore allowing high-resolution multiparametric imaging of soft biological samples under liquid conditions [7,14].

In the first part of this review, we will show how AFM technology used in the different modes described above contributes to understand the effects of antimicrobial molecules on sensitive and resistant microbes, including the mechanisms of action of these molecules and the mechanism of resistance microbes have developed against these molecules. Although AFM has only been used to date as a fundamental research tool, increasing fundamental knowledge on bacterial resistance at the nanoscale and recent technological advances portend that such an instrument could be brought directly into a health-care system. For instance, AFM could be used to provide fast identification of bacteria or yeast in samples from infected patients, as well as fast determination of their susceptibility profile towards antimicrobials. Indeed, providing such diagnosis at the moment requires sub-culturing the sample, using susceptibility testing methods, and identification tests that require at least $24 \mathrm{~h}$ to provide results. Not only would a rapid diagnosis tool greatly benefit patients, but would also reduce costs by reducing working time as well as mortality and morbidity rates. In the second part of this review, we will present the recent advances made towards this goal. One of these developments consists of the development of cell arrays and automation systems for AFM measurements on these arrays. Although this solution is still at an early stage of development, other techniques involving AFM have already proven efficient to diagnose microbial resistance, such as for example the use of nanomechanical sensors.

\section{Topographical and functional imaging of pathogenic microorganisms in interactions with antimicrobial molecules}

In this first section, we will discuss how AFM used in imaging and force spectroscopy modes can reveal the morphological changes induced by antimicrobial treatments on both sensitive and resistant bacterial and yeast strains, as well as the modification of their nanomechanical and adhesive properties induced by these treatments.

\subsection{Antimicrobial treatments affects the morphology of microbial cells at the nanoscale}

One of the most common applications of AFM in microbiology consists of the direct visualization of the morphology of microorganisms [15]. It has been shown in several studies that some antibiotics had an effect on the morphology of bacterial or fungal cells. Pioneer work in the field conducted for example by Braga and Richi showed the morphology changes undertaken by Streptococcus pyogenes cells under rokitamicyn treatment, a macrolide antibiotic [16], or by Bacillus cereus cells after treatment by daptomycin, a lipopeptide antibiotic [17]. Later, work conducted by Soon et al. demonstrated the changes induced by colistin, a last chance antibiotic from the polymyxin class, on the morphology of colistin-resistant Acinetobacter baumannii cells [18]. As for yeast cells and their interactions with antifungals, although only a few studies were conducted to date using AFM, the workof for example Kim et al. showed that allicin, when combined with amphotericin $\mathrm{B}$, a polyene antifungal, induced significant cell wall damage to Candida albicans cells [19]. Then, with the advances made in the field of living cell immobilization, similar studies conducted on living cells in liquid conditions could be performed.Formosa et al. showed the elongation of living Pseudomonas aeruginosa cells under penicillin treatment (ticarcillin) [20], and also the elongation of Saccharomyces cerevisiae cells due to the impairment of cytokinesis induced by caspofungin treatment (echinocandin class) [21].

Antimicrobial treatment does not always involve a chemical molecule. Indeed, inactivating bacterial cells or spores can also be achieved through physical methods, as for example by electroporation. This technique was recently used by Pillet et al. to inactivate both vegetative and spore forms of Bacillus pumilus, a non-pathogenic model of food contaminants [22]. To this end, the authors applied pulsed electric fields (PEF), a method that uses short pulses of 
electricity to inactivate bacterial cells (Fig. 1). After optimization of the PEF parameters, they showed, thanks to AFM imaging in combination with scanning electron microscopy (SEM) and transmission electron microscopy (TEM), that PEF treatment on vegetative cells affected directly the architecture of the cell wall (Fig. 1a-f). Indeed, the peptidoglycan network was ruptured by the PEF treatment, leading to its permeabilization and leakage of the cell's contents. Similar to the spores of B. pumilus, PEF treatment induced damage in the internal parts of the spore (on the cortex and core of the spores), as seen by TEM imaging. Moreover, both SEM and AFM topographical images showed the formation of budding structures at the surface of the coat of the spores, as seen in Fig. 1h, $\mathrm{k}$ and 1 . The coat of B. pumilus spores is composed of protein ridges, conferring resistance and hydrophobicity to the spores. By applying PEF on these spores, the authors in fact modified these protein ridges, and thus decreased the hydrophobic properties of the spores. In summary, this study, using AFM, showed not only that PEF exposure was efficient to inactivate bacterial cells and spores, it also produced evidence that PEF alters the integrity and architecture of the cell wall of bacteria, not only of the cell membrane as it was believed.

However, in most studies, the effects of antimicrobial molecules or treatment are studied after the treatment was applied. Therefore, only the resulting consequences on morphology are quantified. Looking in real time at the effects of antimicrobial treatments, directly on living cells would provide valuable information on the mechanism of action of these treatments, and on the defense mechanisms microorganisms develop against these treatments. This real-time monitoring on live cells is nowadays possible, thanks to AFM technology. Indeed, in recent years High-Speed AFM (HS-AFM) was developed, independently by the groups led by Hansma [23,24] and Ando [25], which thus offered a means to study dynamic molecular processes.
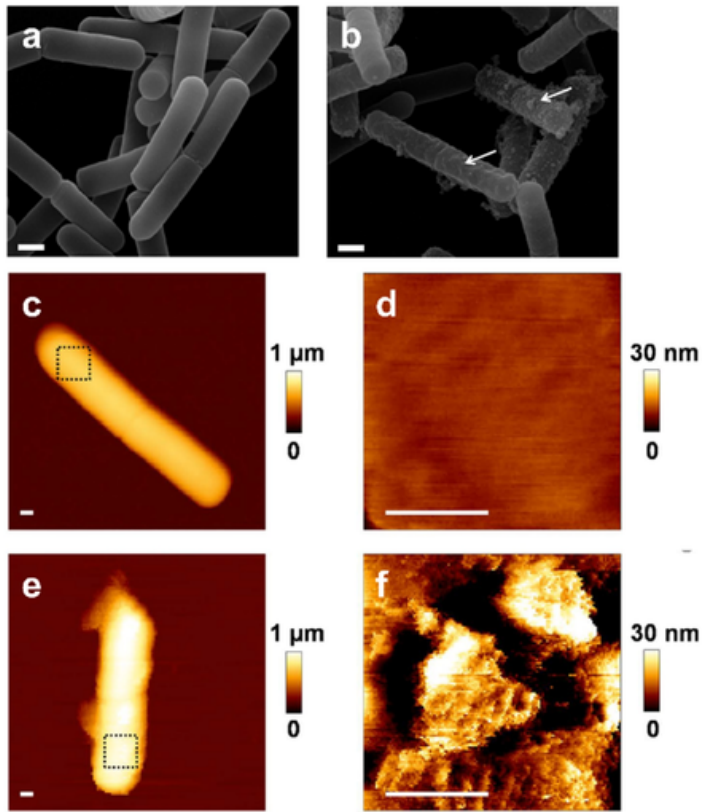

However, in order to increase the imaging speed of AFM, several technological developments had to be made, including (1) short cantilevers able to oscillate at high frequencies while maintaining a low spring constant (2) Z-scanners with no mechanical vibrations; and (3) controllers able to dynamically tune the feedback gains during imaging to minimize the tip-sample forces [26]. HS-AFM has so far been successfully used to image protein dynamics, such as the walking of myosin V on actin filaments [27], and the elongation and retraction of nucleoporins in nuclear pore complexes (NPC) [28]. However, due to the limitation of the small sample height required to perform such experiments, only a few studies were conducted on entire living microorganisms. Fantner et al. used this technique to study the kinetic effects of exposure of E. coli cells to an antimicrobial peptide [29]. Their results, presented in Fig. 2a, led to a complete understanding of the mechanism of action of this molecule, which is in fact a two-step process; a first phase of incubation that can vary from seconds to minutes depending on the cells, and a second execution phase, which in $50 \%$ of the cases is achieved in less than one minute. More recently, a study conducted by Watanabe et al. showed that HS-AFM could be used to image the bacteriolysis process of B. subtilis exposed to lysozyme treatment. Their results showed that lysozyme first induces an increase of the cell surface roughness, with the appearance of wrinkled structures that is followed by a swelling of the cells and their lysis due probably to an excessive osmotic pressure (Fig. 2b) [30]. These two studies offer proof that HS-AFM is a powerful technique to understand the mechanism of action of antimicrobial molecules. Its use on multi-drug resistant microbes could therefore likely highlight the mechanisms of resistance of these microorganisms, which would provide valuable information that could be used to better manage antimicrobial treatments on patients.
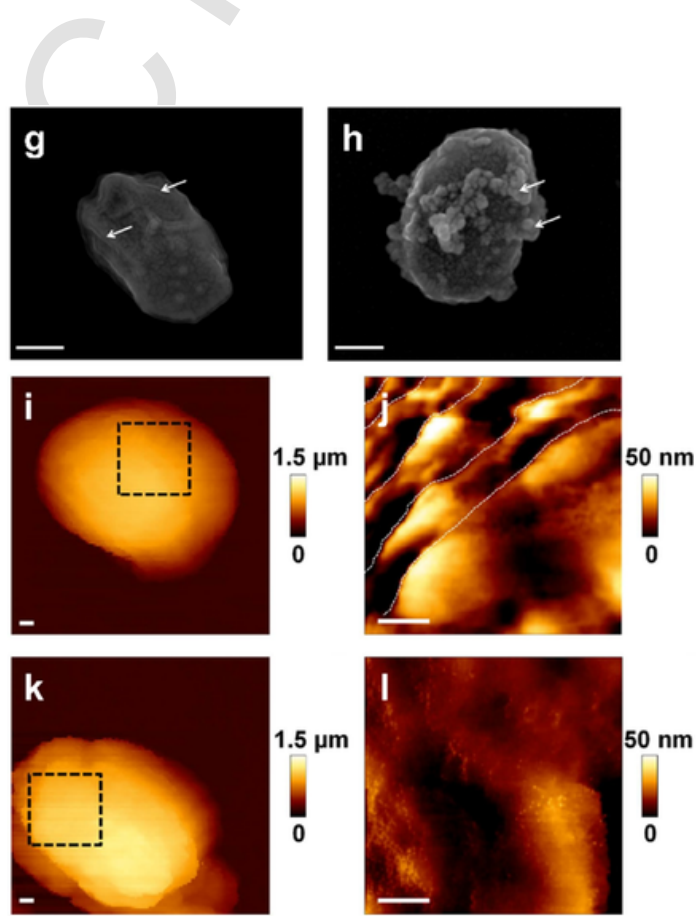

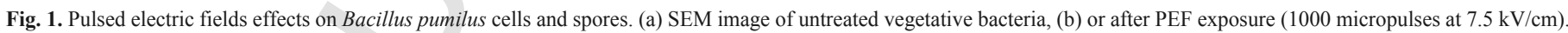

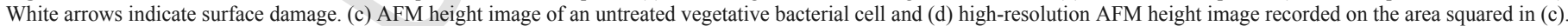

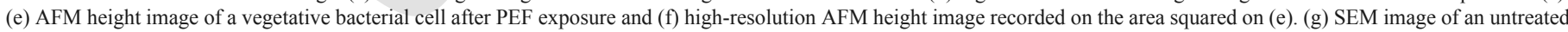

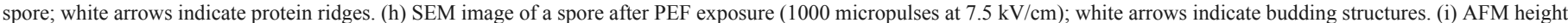

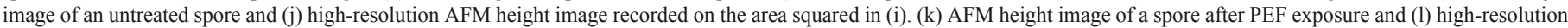
AFM height image recorded on the area squared on (k). Reprinted with permissions from Ref. [22]. 

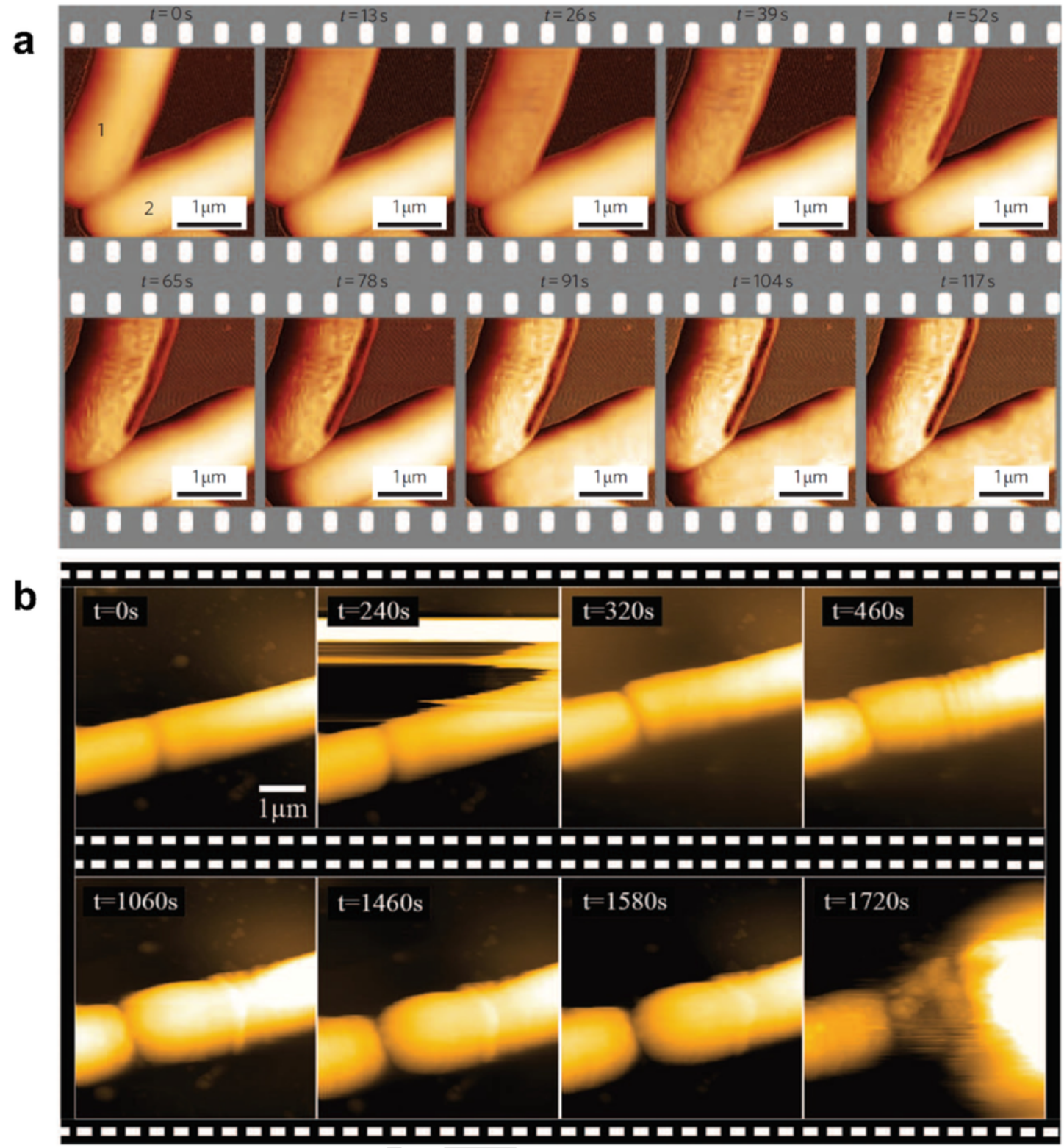

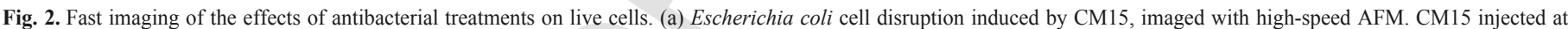

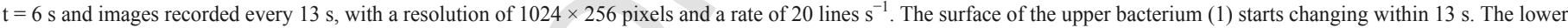

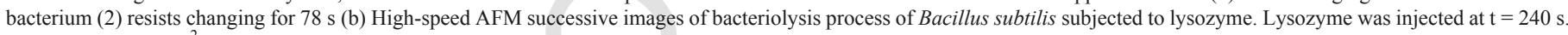
Scan range, $5 \times 5 \mu \mathrm{m}^{2}$; imaging rate, $20 \mathrm{~s} /$ frame; pixels, $256 \times 256$. Reprinted with permissions from Refs. [29,30]

\subsection{Nanomechanical properties of cells influence their response to antimicrobial treatment}

The nanomechanical properties of microbes can be investigated using AFM in force spectroscopy mode, through nanoindentation measurements. These measurements, providing access to the cell wall spring constant (stiffness) or elasticity (Young's modulus), are of first interest as they provide information on the state of the most important microbial component. Indeed, for microbes the cell wall is vital, as it maintains cell shape and integrity, and protects the interior of the cell from the surrounding environment [31]. The cell wall of microbes represents also the first interface that antimicrobial molecules meet during a treatment; many studies have shown that not only its mor- phology was modified upon treatment, but also its mechanical properties, through deep remodelling of its composition and architecture. First examples of such modifications induced by antimicrobials were provided for example by Francius et al., who showed that lysostaphin, an enzyme with a specific activity on peptidoglycan, induced a decrease both in the elasticity and stiffness of living Staphylococcus aureus cells [32]. Additionally, Mortensen et al. showed on P. aeruginosa cells that colistin induced an increase of the cell wall stiffness after only two hours of exposure [33]. As for yeast cells, antifungal treatments also are able to modify their cell wall nanomechanical properties. In a recent study, the effects of caspofungin, a last chance antifungal molecule from the echinocandin class, were probed using nanoindentation measurements on the cell wall of the human pathogen Candida albicans [21]. The authors of this study 
showed that an increasing dose of caspofungin led to a gradual increase of the Young's modulus of the cell wall. By combining these analyses with biochemical determination of the composition of the cell wall of the cells, the authors could directly correlate the Young's modulus to the chitin content of the cell wall. Indeed, caspofungin treatment induces a remodeling of the architecture of the cell wall by inducing an increase of the chitin production, a rigid polymer naturally present in C. albicans cell wall, thus increasing the Young's modulus.

The cell wall changes induced by antimicrobial molecules can also have consequences on the behavior of the microbial cells in direct applications in health-care systems, such as the sterilization of fluids by microfiltration, for example. This aspect was recently explored by Gaveau et al. using AFM. In this study [34], the authors treated the three bacterial species most often involved in nosocomial infections, $S$. aureus, $P$. aeruginosa and $E$. coli, with $\beta$-lactam antibiotics that specificically target the peptidoglycan of bacteria. The results obtained through nanoindentation measurements revealed that antibiotics, by inducing a decrease of the elasticity of the bacteria cell walls, made the bacterial cells more deformable. This led to an amplified transfer of the cells through the pores of the membranes used in filtration (pore size of $0.4 \mu \mathrm{m}$ ) and thus to a lowered retention efficiency by the membrane. The authors varied the filtration parameters and developed a numerical model to connect the retention efficiencies measured in their different conditions with the nanomechanical properties of the bacterial cells. The conclusions reached from this work suggest that treating cells with antimicrobials, at least at the sub-lethal concentrations that were used in this study, unwanted consequences may occur, such as the amplification of the contamination on the filtrated fluids.

But nanomechanical studies cannot be reduced only to the quantification of elasticity or stiffness. Indeed, nanomechanical measurements, when used on certain microbes can reveal the architecture of ultrastructure present at the surface of cells. In this view, recent studies focused on the bacterial species Klebsiella pneumoniae, which presents on its urface a thick capsule composed of a polysaccharidic polymer, in which are embedded the lipopolysaccharide (LPS) as well as surface appendages like fimbriae. A first study conducted in 2013 by Wang et al. showed through nanoindentation measurements the role of the architecture of this capsule in resistance of K. pneumoniae cells to osmotic pressure [35]. The authors performed the experiments on different strains of $K$. pneumoniae either expressing or not expressing the capsule, exposed to extreme osmotic conditions (variation of the electrolyte concentration in the media). The resulting force curves of these experiments were fitted through several physical models described in Fig. 3a, which allowed the authors to provide an understanding of the biophysical behavior of the capsule under osmotic stress. Using this methodology, they could then determine that under low electrolyte conditions, the capsule is hydrated and organized as a polymer brush, whereas under high electrolyte concentration, this brush is partially collapsed and dehydrated. They concluded that the capsule of $K$. pneumoniae behaves like an ion sponge, protecting the cells from osmotic stress by ensuring they maintain viable cytoplasmic turgor pressure. The question then arises if this capsule is also able to protect cells from an antibiotic treatment? Formosa et al. answered thius question in a recent study conducted in 2015 [36]. In this study the effects of colistin, a last chance antibacterial from the polymyxin class, were probed on both sensitive and colistin-resistant strains of $K$. pneumoniae, using AFM in force spectroscopy mode. Their local nanoindentation measurements showed that the capsule was organized differently depending on the strains. Indeed, for the sensitive strain, the force curve analysis revealed that the cap- sule was organized in a soft monolayer of polysaccharides, whereas for the resistant strain, the capsule was harder and structured in several superimposed layers (Fig. 3b). Upon treatment by colistin, only the capsule of the sensitive strain was removed by the treatment, whereas the capsule of the resistant strain remained. By combining this biophysical analysis with genotypic studies, the authors showed that in the resistant strain, the $\operatorname{mgr} B$ gene was in fact inactivated, which leads to a modification of the LPS present in the capsule. Therefore, using nanoindentation measurement combined with genetic studies, the authors established a link between the composition of the capsule and its architecture, and showed that this capsular architecture was in fact playing a key role in the protection of the cells from colistin treatment. However, this resistance mechanism cannot be generalized to all strains of $K$. pneumoniae, as determined by Mularski et al. in a study conducted on different sensitive and colistin-resistant strains of $K$. pneumoniae [37]. Their interpretation of force curves and capsule thickness observations led them to hypothesize that the capsule organization had no physical role in colistin resistance, as Formosa et al. suggested for the strains they used. For Mularski strains, the remaining capsule on the resistant strain upon colistin treatment was due to the modification in this strain of the LPS caused by a mutation in the PrmB sensor kinase. This, as the authors suggest, reduces the negative charge of the outer membrane of the cells, affecting the electrostatic interactions between colistin and LPS, thus leading to the maintenance of the capsule on the cells. However on these strains, no particular architecture of the capsule was observed, as shown on the force curve presented in Fig. 3c, perhaps explaining the differences between the two studies. But what is interesting to remember is that with similar observations, $i$. e. the maintenance of the capsule upon colistin treatment for colistin-resistant strains, different genetic mutations were identified, and different mechanisms of resistance were proposed. This confirms the usefulness of a technique as sensitive as AFM to explore not only microbial resistance mechanisms in different species, but also in different strains of the same species.

\subsection{Probing the adhesive properties of microbes using AFM technology}

Adhesion, to surfaces or to other cells, is a key parameter for microbes. Indeed, while adhesion to host surfaces often represents the first stage of an infection process, adhesion to abiotic surfaces or between cells are also major steps in the formation of biofilms. Therefore, studying these adhesion mechanisms directly at the surface of microbes, when they are interacting with antimicrobials for example, or in native conditions, provides a wealth of information for developing new antimicrobial strategies. For this purpose AFM is particularly well-suited, as it can probe the interactions directly on living cells using unmodified or AFM tips bio-modified with single molecules or single cells. Using unmodified tips, it is already possible to monitor for example the effects of antimicrobial molecules on the adhesion properties of cells. Formosa et al. showed with the pathogenic yeast $C$. albicans that exposure to a small dose of caspofungin led to the overexpression of an adhesive protein (Als1p) at the surface of the cells that could be probed using AFM [21]. In another study conducted by Tajkarimi et al., unmodified tips were used to measure non-specific adhesion forces on sensitive and resistant strains of the bacterial species Listeria innocua and E. coli to disinfectant agents (silver and benzalkonium chloride) [38]. Interestingly the authors of this study showed that the "stickiness" of the strains was different depending on their susceptibility profile, whereby the resistant strains displayed increased adhesion forces compared to the sensitive strains. 


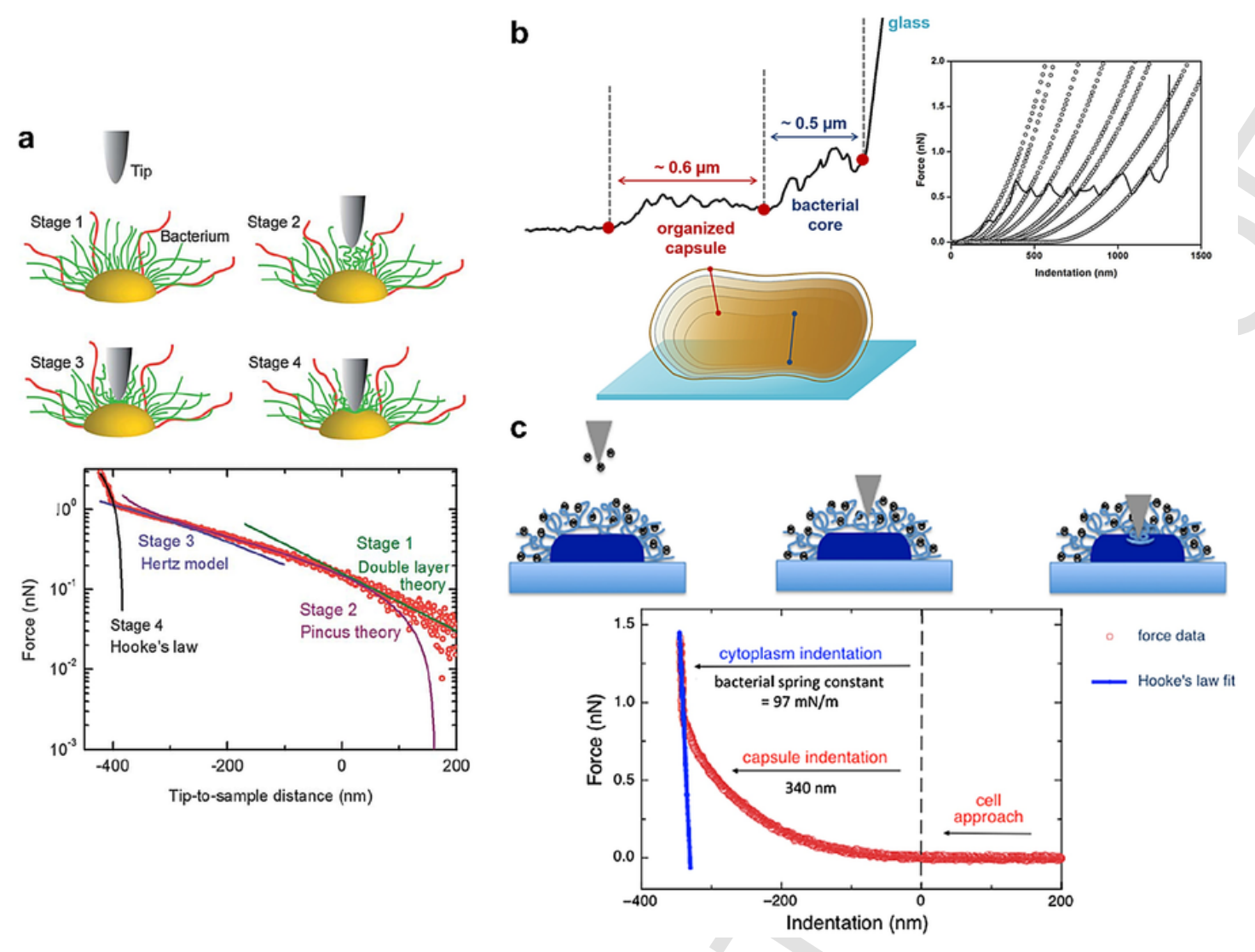

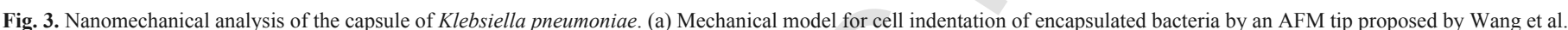

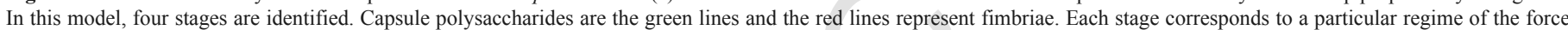

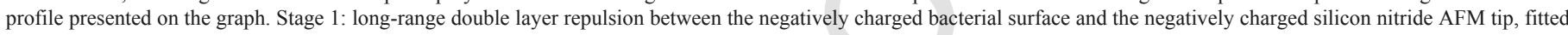

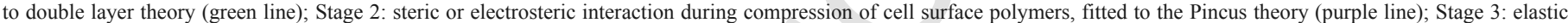

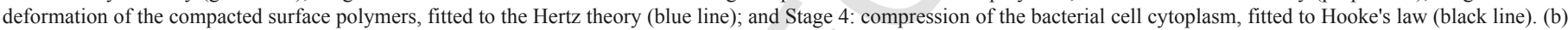

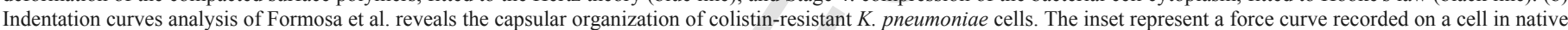

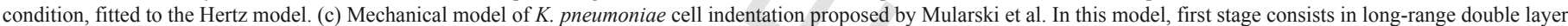

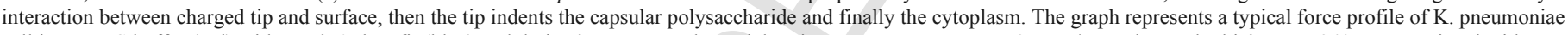

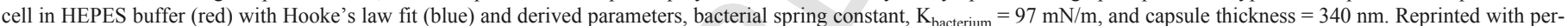
mission from Refs. [35-37].

Therefore, the authors, by measuring the adhesive properties of bacteria, could develop a method to rapidly determine if bacterial cells are resistant or not to antimicrobials.

Functionalizing AFM tips with biomolecules allows the direct mapping of specific interactions at the surface of cells at the single-molecule scale. For example, Gilbert et al. used tips functionalized by vancomycin, a glycopeptide used as a last-chance antibiotic, to probe the cell surface of Lactococcus lactis, a model Gram-positive bacterial strain [39]. This antimicrobial molecule is known to specifically bind the D-Ala-D-Ala precursors of newly formed peptidoglycan. Using this system, the authors mapped these specific binding sites at the surface of cells and showed that the action of vancomycin directly targeted the cellular division process, since adhesive events were only recorded at the septum of dividing cells. Single-molecule force spectroscopy can also be used to understand the mechanism of action of new antimicrobial molecules. Indeed, in an effort to confront bacterial resistance, new innovative molecules, against which no resistance mechanisms have yet been developed, are currently being evaluated for their antimicrobial efficiencies. Calixarenes are an example of these innovative molecules; they have been shown to present antibacterial activities to both Gram-positive and Gram-negative bacterial species [40], although their mechanism of action was still unknown. In 2012, a study used functionalized AFM tips to determine the mechanism of action of one of these calixarene molecules, named Cx1, on the bacterial species Pseudomonas aeruginosa [41]. The authors probed the cell surface of $\mathrm{Cx} 1$ treated cells with tips functionalized with the lectin Concanavalin A that binds to carbohydrate molecules such as peptidoglycan. The results of these experiments showed that peptidoglycan could be directly unfolded only from the surface of treated cells. By combining these results with imaging data obtained on $\mathrm{Cx} 1$ treated supported phospholipidic membranes, the authors hypothesized that the calixarene, presenting a high positive charge, was in fact interacting with the negatively charged surface of the Gram-negative bacteria and thus destabilizing it. This mechanism of action indicates that the inner peptidoglycan could be unfolded from the treated cells using the functionalized AFM tip.

AFM tips can also be directly functionalized using single-cells. This method, recently adapted to microbial studies [42], allows the directquantification of the interactions between a cell and a surface for example, but also between two different cells. Indeed, a powerful means for microbes to resist an antimicrobial treatment is through formation of a biofilm. Biofilms are defined as cell communities protected by extracellular matrix, resulting in resistance to antimicrobial treatments [43]. Understanding the molecular mechanisms underlying biofilm formation would greatly contribute to the struggle against bacterial resistance, by allowing the evaluation and identification of 
anti-adhesion compounds that would inhibit the formation of these biofilms. Recent studies have shown the ability of single-cell force spectroscopy to address this important issue. Beaussart et al. used this technique to evaluate the activity of novel antiadhesive compounds, mannofullrenes, which exhibit mannose residues capable of interfering in the adhesion process of uropathogenic E. coli strains to mannose moieties found on host epithelial cells [44]. E. coli cells were used to functionalize AFM colloidal probesto measure the adhesion forces with mannose-coated surfaces before and after addition of mannofullrenes in the media at different concentrations. The results of these experiments showed that the adhesion of cells to mannose surfaces decreased gradually with the mannofullrene concentration, therefore showing the efficiency of the molecule to block attachment of cells to host surfaces. In another recent study, the same technique of single-cell force spectroscopy was usedto evaluate the activity of a new anti-adhesive compound on both the surface adhesion and the cell aggregation processes involved in biofilm formation by the bacterial pathogen $S$. aureus [10]. The authors were particularly interested in the interactions mediated by the staphylococcal surface protein SdrC. After showing that these proteic interactions were involved in both cell-surface attachment and cell-cell interactions, they used molecular modelling to identify a peptide derived from the neuronal cell-adhesion molecule $\beta$-neurexin able to bind to a specific site of the SdrC protein (Fig. 4a). Single-cell force spectroscopy experi- ments were then used to evaluate the anti-adhesion activity of this peptide; the results presented in Fig. $4 \mathrm{~b}$ showed that the peptide was indeed efficient to block the SdrC-mediated cell-cell adhesions, as well as the adhesion of SdrC presenting cells to abiotic surfaces. These two studies demonstrate that AFM studies with probes functionalized with single-cells can be used to understand adhesion processes involved in biofilm formation by pathogenic bacterial species, and additionally; serve as a valuable tool to evaluate the efficiency of newly developed anti-adhesive agents and show their potential as antimicrobials.

In conclusion, we have shown in this section how AFM can be used not only to address the question of antimicrobial therapy and resistance, but also of bacterial pathogenicity and virulence. Its imaging capabilities, combined with its sensitive force measurement capacities and the possibility to modify tips make AFM a valuable technology to address clinical microbiology issues. However, all the studies presented data obtained from individual cells. Indeed, AFM is still a single-cell technology. In order to go a step further, and bring this technology to for example a hospital lab, and use it as a method to rapidly determine antimicrobial susceptibility, or strain identification, this single-cell paradigm needs to be advanced. AFM needs to develop into a high-throughput technology able to image or measure forces on entire microbial populations in a limited timeframe. a

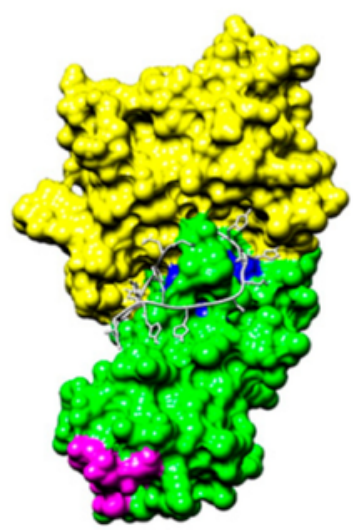

b

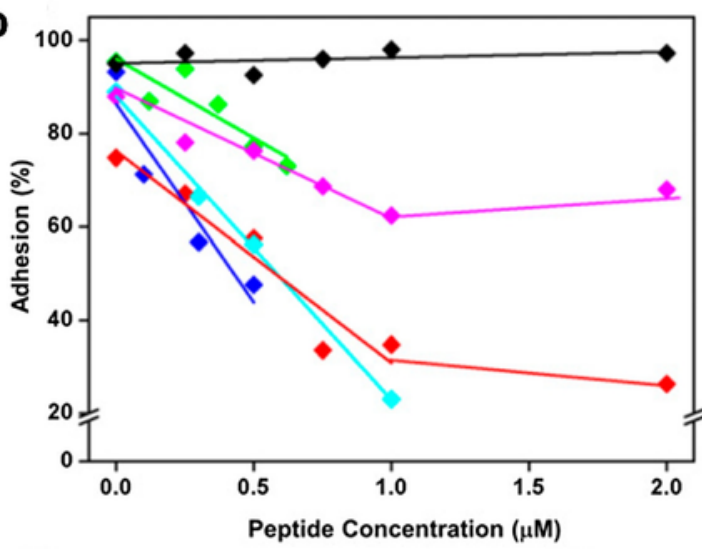

RPGSV

VDQYT
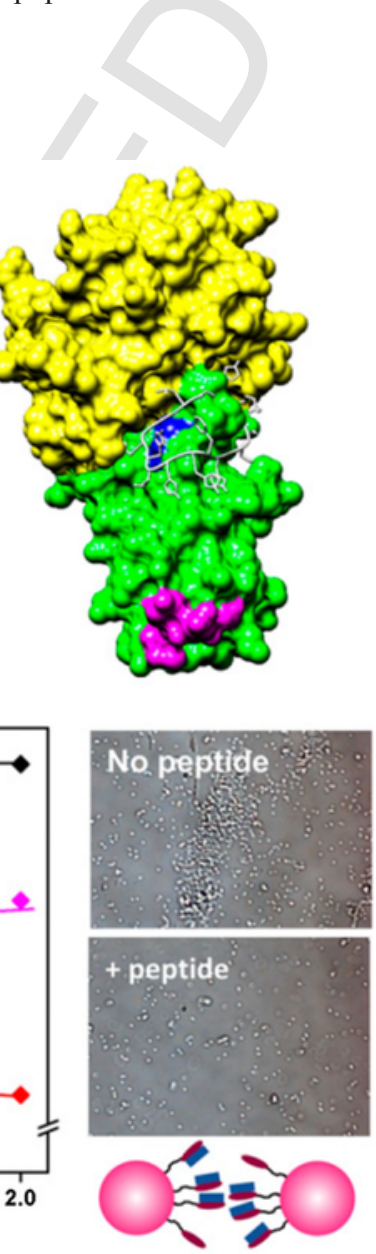

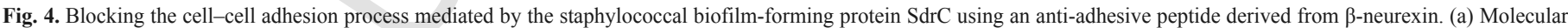

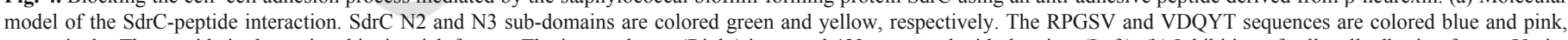

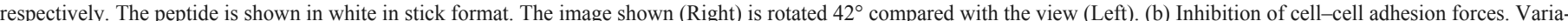

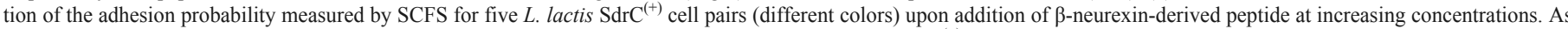

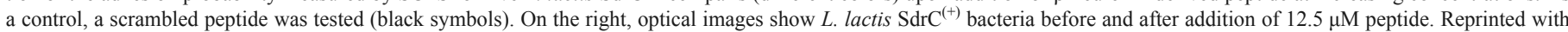
permission from Ref. [10]. 
3. Changing AFM paradigm: from single-cell technology to a high-throughput instrument

In the fight against microbial resistance, high-throughput technologies are required. Indeed, developing tools that can rapidly detect and characterize the response of populations of microorganisms to an antimicrobial would greatly aid in providing quick and efficient treatments in the case of infections involving multi-drug resistant bacteria or yeasts. Several strategies have been recently proposed to increase experimental throughput using AFM technology. While one of these strategies is focused on creating organized cell arrays, other strategies take advantage of the AFM cantilevers by using them directly as nanomechanical sensors or by adapting them with microfluidic systems.

\subsection{Creating microbe arrays for AFM measurement}

The first requirement for performing AFM experiments on biological samples is to immobilize these samples. Indeed, since the tip exerts mechanical forces on the cells, they must be immobilized firmly to withstand these forces. Moreover, the immobilization strategy should not denature the cell interface properties. Several techniques have been already used to immobilize cells for AFM experiments. A simple method is to fix them chemically on a solid substrate using glutaraldehyde [45], or by air drying [46]. Although these methods tallow imaging of the microorganism's ultrastructural features such as fimbriae or flagella, they modify the interface of the sample by killing the cells. Seeking non-denaturing immobilization methods for living cells, two different strategies have emerged. One of them takes advantage of the electrostatic interactions between a positively charged surface, such as a polyethylenimine (PEI) coated glass slide, and a negatively charged sample, such as a bacterial cell [47]. The other strategy consists of mechanically trapping round shaped cells such as bacterial cocci or yeasts in the pores of a polycarbonate membrane [48], or in microstructured polydimethylsiloxane (PDMS) stamps [49].

Using these two strategies, techniques were then developed to direct the immobilization of microbes onto predefined zones on substrates to create arrays of living cells. One of the first studies in this field is by Cerf et al., who immobilized single bacterial cells using electrostatic interactions on APTES patterned surfaces (glass or silicon) (Fig. 5a). Although APTES can be toxic for bacterial cells, the authors developed a fast and reliable method to create patterned cells, and could compare the nanomechanical properties of $E$. coli cells before and after inactivation by heat treatment (Fig. 5b and c) [50]. In
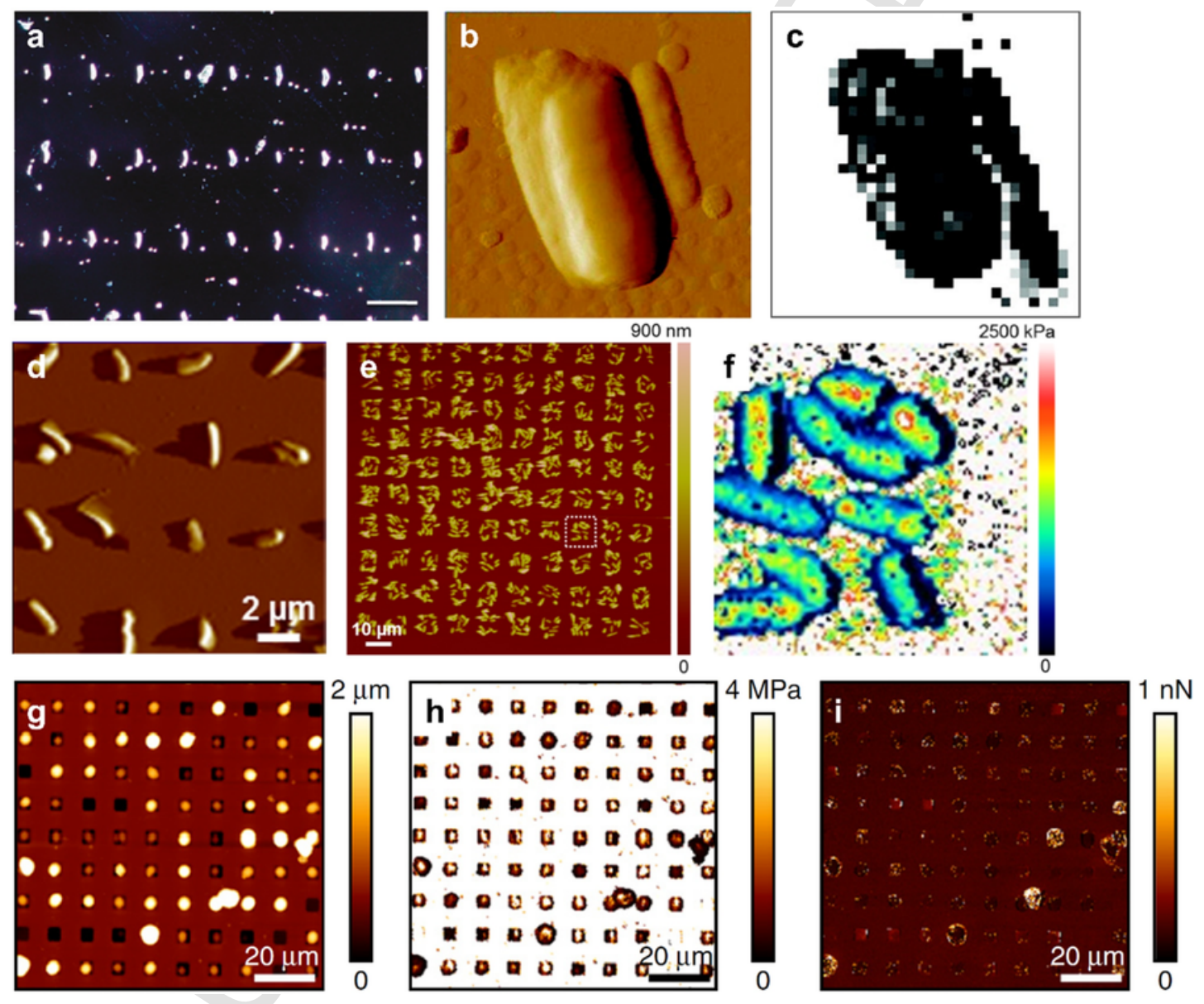

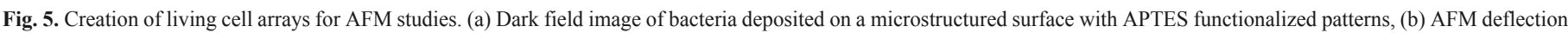

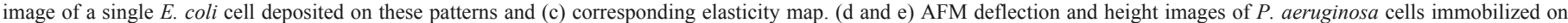

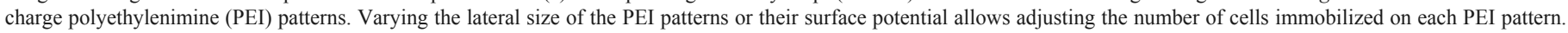

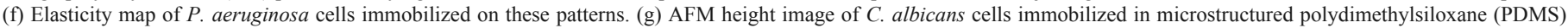
stamps, and its corresponding elasticity (h) and adhesion images (i). Reprinted with permissions from Refs. [49-51]. 
an effort to create bacterial arrays using non-toxic chemicals such as 3-Aminopropyltriethoxysilane (APTES), Jauvert et al., developed a technique to develop patterns of PEI on poly(methyl methacrylate) (PMMA) substrates by nanoxerography [51]. These substrates presenting positive charges in confined places, were then incubated in a suspension of Pseudomonas aeruginosa, leading to the electrostatic immobilization of the cells on the patterns. The cell viability was tested and PEI thin films were found to have no effect on the cell membrane permeability to propidium iodide (fluorescent dye used in the live/dead bacterial assay). They then imaged by AFM arrays of PEI patterns on which 1-10 bacteria were immobilized, depending on the charge density and the size of these patterns (Fig. $5 \mathrm{~d}$ and e). They also measured the nanomechanical properties of each cell on a pattern and rapidly determined elasticity measurements for 10 different cells (Fig. 5f). Finally in another study, Arnfinnsdottir et al. patterned polydopamine using a micro-contact printing technique on anti-adhesive polymers [52], allowing the organization of thousands of living E. coli cells that could be further used for single cell analysis.

Formosa et al., used PDMS stamps to immobilize yeast cells $(S$. cerevisiae and C. albicans), algae (Chlorella vulgaris), and round organites from mammalian cells (nuclei) to create arrays for round-shaped samples that cannot be immobilized on flat surfaces. $[7,49]$. The PDMS stamp the authors used reproduces the microstructure of a silicon master generated by photolithography and reactive ion etching (RIE). The patterns designed on this silicon master are squares of $1.5-6 \mu \mathrm{m}$ wide that form an array of holes in the PDMS stamp (which is the negative reproduction of the silicon master). Round shaped cells can then be trapped mechanically in these holes by convective capillary deposition, which constitutes an efficient method to reach high rates of hole filling. For instance, for C. albicans cells, filling rates of $85 \%$ were obtained by the authors, therefore making it possible to analyze the heterogeneity of the cell population. Moreover, using advanced multiparametric imaging modes, both height of the sample and its surface properties (nanomechanical and adhesive properties) can be recorded in one acquisition. Such results are presented in Fig. 5g-i. In this example, the scan performed on 85 cells shows that the adhesive properties are not homogeneous amongst the cell population, as a few cells (actually 3/85) show higher adhesion forces towards the unmodified AFM tip (Fig. 5i).

These examples illustrate the fact that cell patterning is becoming a topic of increasing interest. Indeed, in clinical microbiology, cell patterning represents both the first step towards testing antimicrobial drugs or agents on single microbes, and additionally a required method to test and analyze a microbe population heterogeneity. We are concerned in this review with microbes only, but cell arrays were also developed for mammalian cells; for example, patterning of extracellular matrix proteins by micro-contact printing was used to reconstruct an average fluorescent or mechanical cell $[53,54]$. Although this approach of averaging the results might lead to a loss of information, mechanical or adhesion spectrum data that would provide more information could also be obtained using such techniques. In this perspective an automated AFM will be mandatory in the near future to perform mechanical or adhesion experiments on hundreds of cells. In this system, the AFM tip will "fly" from cell to cell, patterned on defined position, constructing cell after cell, the mechanical or adhesive spectrum of the microbe population in response to antimicrobial treatment for example. Such systems could also be used to analyze cells isolated from a tumor, or from any other biopsy, which would constitute an advance in the transfer of AFM technologies to the hospital setting where could serve in a diagnostic capacity.

\subsection{Nanomechanical sensors and other innovative strategies involving AFM}

As a result of its high sensitivity, AFM also offers the possibility of using cantilevers as label-free nanomechanical biosensors. The basic principle of nanomechanical sensors is that molecular recognition between targeted molecules present in a sample solution and sensor-anchored receptors leads to a change of the mechanical properties that can be transduced by the sensor [55]. But these types of cantilevers can also be used to transduce small nanoscale vibrations emitted naturally by living systems. While this possibility had already been exploited in 1999 to monitor the contractile behavior of living cardiomyocytes, it was first used for microbial studies in 2004 by Pelling et al., who used cantilevers to detect the nanomechanical motion of living yeast cells in physiological media [56]. The authors measured, while in contact with the cells, the cantilever motion as a function of the time, in an acoustically isolated environment. Their results showed that in native conditions, the cell wall motion of cells was clearly oscillatory with an average amplitude around $3 \mathrm{~nm}$. Using sodium azide, a yeast metabolic inhibitor, they showed that these motions were in fact due to metabolic processes taking place inside the cells, since after treatment the cell's motion had an average amplitude reduced to approximately $0.4 \mathrm{~nm}$. Therefore AFM was used in this study to look at the effects of a treatment on the "inside" of yeast cells, in a non-invasive manner, without the use of chemical or fluorescent dyes. This pioneer work opened the way to other studies performed mainly by the group of Kasas in Switzerland, in which AFM cantilevers are used for measuring a living microbe's motions, interacting with or without antimicrobial molecules. Indeed, this team developed a method in which living bacteria are immobilized on a cantilever sensor, and fluctuations are monitored using an AFM [57]. Movements of the bacteria on the cantilever cause an increase in the amplitude of the fluctuations of the sensor that vary depending on the medium used. Analysis of the time-dependent fluctuation charts obtained then provide information on the metabolic activity of bacteria. In experiments performed by the authors using this method, cells of $E$. coli were attached to a cantilever, which induced an increase in the fluctuations of the cantilever. After addition to the medium of a penicillin antibiotic (ampicillin), the fluctuations of the cantilever decreased to low values, close to the ones obtained with a cantilever with no bacteria attached (Fig. 6a). However, when the medium is complemented with glucose, fluctuation of the cantilever increases again. These results show the link between high fluctuations and the bacterial metabolic activity: when bacteria are in a medium that promotes metabolic activity, fluctuations increase, and when they arekilled by an antibiotic, fluctuations decrease. But an interesting point is that, taking advantage of the sensitivity of this method, the authors, by introducing increasing concentrations of the antibiotic in the medium, detected the concentration for which fluctuations started to decrease and thus could calculate the minimal inhibitory concentration of the antibiotic towards the bacterial strain tested. Therefore, this method represents a fast and high-throughput way to determine the antibiotic susceptibility of bacterial strains, which constitutes a big step towards using AFM technology in health-care systems. The authors also showed the versatility of this method by performing similar experiments on a resistant strain of E. coli, on Gram-positive bacteria, and on fungal and mammalian cells [58]. In the case of the resistant strain, the fluctuations of the cantilever first decreased upon addition of the antibiotic, before increasing again, after 15-20 min, returning to values obtained before exposure to the antibiotic, then showing that resistant bacteria first undergo a metabolic shock before 
a
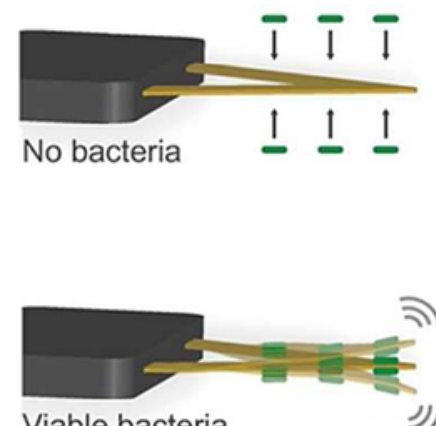

Viable bacteria

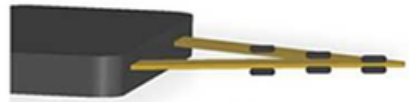

Exposure to antibiotics
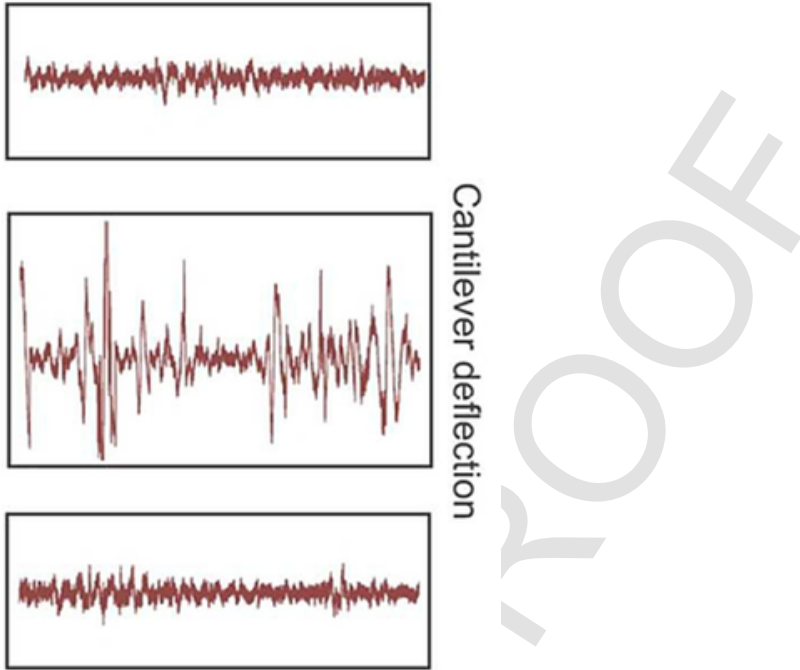

\section{b}

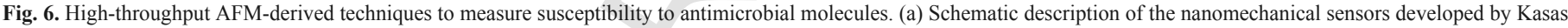

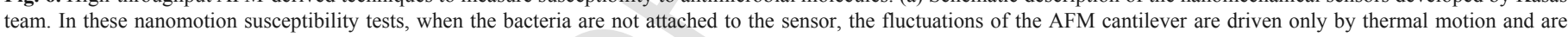

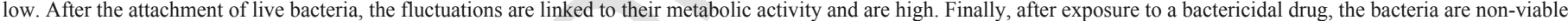

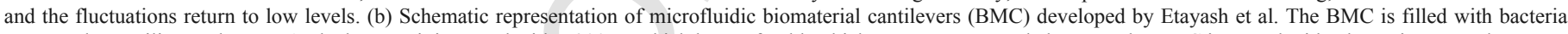

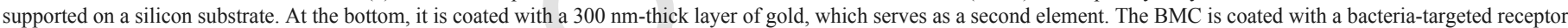

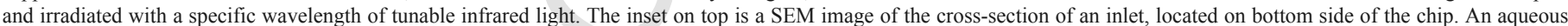

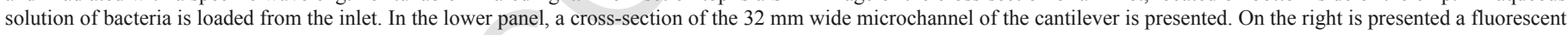

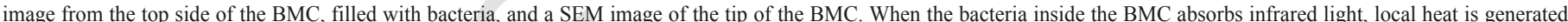

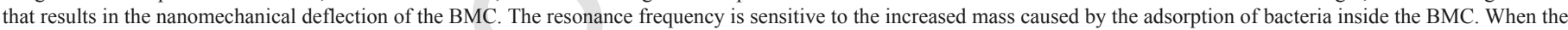

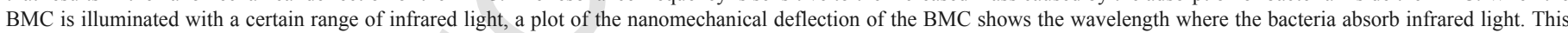
can provide excell.

adapting to the presence of the antibiotic in the medium. Very recently the same team showed the utility of this method in medical applicationsby using it to detect the susceptibility profile of bacterial strains directly in blood culture pellets [59].

Another approach also takes advantage of the sensitivity of the AFM system and cantilevers to perform susceptibility testing for large populations of microbes, by adapting these cantilevers with microfluidic systems. This particular approach was developed in a recent study by Etayash et al. [60]. It consists of a bi-material cantilever (BMC) with an embedded microfluidic channel with internal surfaces that can be chemically or physically functionalized with receptors. These receptors then capture bacteria in a suspension passing through the channel; their adsorption inside the cantilever results in changes in the cantilever deflection, similar to the Kasas system, but also in the resonance frequency, providing information on the mass of cells adsorbed. This system also includes a third mode of detection, through the excitation of the trapped bacteria using an infrared radiation that causes the cantilever to deflect in proportion to the infrared absorption of the bacteria. Its principle is represented in Fig. 6b. Through this three-detection modes system, this device can serve for 
both bacterial strain identification and quantification, and additionally for susceptibility testing. The authors of the study detected in a suspension Listeria monocytogenes cells using a BMC coated either with anti-L. monocytogenes monoclonal antibodies or with a L. monocytogenes-targeted antimicrobial peptide. The results showed that $L$. monocytogenes bacterial cells could be detected selectively from other bacterial species, with a detection limit of a single cell per $\mu \mathrm{L}$. In another experiment performed in this study, the authors functionalized the surfaces of the BMC with APTES in order to immobilize E. coli cells. Growth medium containing different antibiotics were then injected in the cantilever, which conducted to changes in resonance frequency and cantilever deflection, therefore showing a clear effect of the antibiotics on the bacterial cells.

In conclusion, this last section shows that AFM technology, thanks to its nanoscale sensitivity, and combined with the technological developments described here (cell arrays generation, nanomechanical sensors), is not limited to single-cell analysis. It can indeed become a high-throughput technology, used in clinics to identify microbial strains in a fluid, and to determine the susceptibility profiles of these microbes towards antimicrobials with high sensitivity. These are key steps in the choice of a treatment for a patient presenting with a microbial infection. New recommendations specifiy not using an antimicrobial on a patient without having identified the pathogens, with the aim of controlling resistance proliferation [4]. But in some cases of blood-stream infections for example, time is crucial in the patient diagnosis. The technological advances presented here would then allow the shortenening in a significant way the time needed to perform these analyses and therefore greatly contribute to a patients' well-being.

\section{Conclusion}

After several decades of using every new antimicrobial molecule available, microbial resistance has developed and spread all over the world, leading societies back to what can be called the "pre-antibiotic era". Although antibiotics and antifungals have revolutionized the way of treating infections, they are now to be used with high precaution, especially for new antimicrobials against which no resistance mechanisms have emerged yet. The research effort to fight against microbial resistance has therefore become a necessity. This effort has developed into two different axes; the search for new antimicrobial molecules on one side, and the development of fast and reliable identification and susceptibility testing tools on the other. Although new antimicrobial molecules would greatly and immediately benefit the overall situation, microbes will always be faster and outrace us by developing new ways to resist. Therefore the second axis, developing new tools, appears to be a strategic way to win the fight against microbial resistance in the long run. In this context, AFM, a tool originally developed by physicists, has shown in the last two decades its capabilities for addressing clinical microbial issues. Indeed, we have seen in this review that its high-resolution imaging ability combined with its force probing of cells' surface properties, make it an ideal tool to understand the behavior of microbes towards antimicrobial molecules (antibiotics, antifungals, antimicrobial peptides), and more broadly, to antimicrobial treatments (electroporation, filtration). In a short amount of time, a large number of studies have been performed, with only a selection of them described in this reviewdemonstrating the large interest this technology triggers for microbiologists and clinicians who use it to understand microbial responses to antimicrobial treatments. The generation of this knowledge forms the basis for breaking the paradigm that AFM is only a single-cell technology confined to fundamental research. And it is very recently that this situa- tion started to evolve, as some researches saw the potential of this technology to provide methods to quickly and reliably identify and characterize microbes at the population scale. Indeed, several research teams have brought developments to the AFM towards this goal, which focus on the two major components of AFM systems; the cantilever and the sample. While one strategy is to develop arrays of cells on which AFM measurements could be multiplexed to analyze large numbers of cells, the other strategy uses cantilevers as mechanical sensors to identify and test the susceptibility profile of microbes. But the aim of each strategy is the same: develop new methods to understand and stop microbial resistance, using the high potential and high sensitivity of AFM.

\section{Uncited reference}

\section{Acknowledgments}

E.D. is a researcher of the Centre National de la Recherche Scientifique (CNRS). This review idea raised from projects supported by the Young Scientist Program of ANR (Agence Nationale de la Recherche), project ANR-11- JSV5-001-01, no. (SD) 300243 31, a grant from Direction Générale de l'Armement (DGA) for the 3-year Ph.D of CFD. CFD is now a postdoctoral researcher supported by the AgreenSkills fellowship programme, which has received funding from the EU's Seventh Framework Programme under grant agreement No. FP7-609398 (AgreenSkills+contract).

\section{References}

[1] J. Davies, D. Davies, Origins and evolution of antibiotic resistance, Microbiol. Mol. Biol. Rev. 74 (2010) 417-433, http://dx.doi.org/10.1128/MMBR 00016-10.

[2] H.W. Boucher, G.H. Talbot, J.S. Bradley, J.E. Edwards, D. Gilbert, L.B. Rice, M. Scheld, B. Spellberg, J. Bartlett, Bad Bugs, No drugs No ESKAPE! an update from the Infectious Diseases Society of America, Clin. Infect. Dis. 48 (2009) 1-12, http://dx.doi.org/10.1086/595011.

[3] C.T. Walsh, T.A. Wencewicz, Prospects for new antibiotics: a molecule-centered perspective, J. Antibiot. (Tokyo) 67 (2014) 7-22, http://dx.doi.org/10. 1038/ja.2013.49

[4] Jim O'Neill, Tackling drug-resistant infections globally: Final report and recommendations, (2016). https://amr-review.org/.

[5] J.L. Martínez, T.M. Coque, F. Baquero, What is a resistance gene? Ranking risk in resistomes, Nat. Rev. Microbiol. 13 (2015) 116-123, http://dx.doi.org/10. 1038/nrmicro3399.

[6] G. Binnig, C.F. Quate, C. Gerber, Atomic force microscope, Phys. Rev. Lett. 56 (1986) 930-934.

[7] L. Chopinet, C. Formosa, M.P. Rols, R.E. Duval, E. Dague, Imaging living cells surface and quantifying its properties at high resolution using AFM in QITM mode, Micron Oxf. Engl. 199348 (2013) 26-33, http://dx.doi.org/10.1016/j. micron.2013.02.003.

[8] F. Pillet, L. Chopinet, C. Formosa, É. Dague, Atomic force microscopy and pharmacology: from microbiology to cancerology, Biochim. Biophys. Acta BBA 1840 (2014) 1028-1050, http://dx.doi.org/10.1016/j.bbagen.2013.11.019.

[9] C. Formosa, V. Lachaize, C. Galés, M.P. Rols, H. Martin-Yken, J.M. François, R.E. Duval, E. Dague, Mapping HA-tagged protein at the surface of living cells by atomic force microscopy, J. Mol. Recognit. 28 (2015) 1-9, http://dx.doi.org/ $10.1002 / \mathrm{jmr} .2407$.

[10] C. Feuillie, C. Formosa-Dague, L.M.C. Hays, O. Vervaeck, S. Derclaye, M.P. Brennan, T.J. Foster, J.A. Geoghegan, Y.F. Dufrêne, Molecular interactions and inhibition of the staphylococcal biofilm-forming protein SdrC, Proc. Natl. Acad. Sci. U. S. A. 114 (2017) 3738-3743, http://dx.doi.org/10.1073/pnas. 1616805114.

[11] C. Formosa-Dague, C. Feuillie, A. Beaussart, S. Derclaye, S. Kucharíková, I Lasa, P. Van Dijck, Y.F. Dufrêne, Sticky matrix adhesion mechanism of the staphylococcal polysaccharide intercellular adhesin, ACS Nano 10 (2016) 3443-3452, http://dx.doi.org/10.1021/acsnano.5b07515.

[12] C. Formosa-Dague, P. Speziale, T.J. Foster, J.A. Geoghegan, Y.F. Dufrêne, Zinc-dependent mechanical properties of Staphylococcus aureus biofilm-forming sur- 
face protein SasG, Proc. Natl. Acad. Sci. 113 (2016) 410-415, http://dx.doi.org/ 10.1073/pnas.1519265113.

[13] C. Formosa-Dague, Z.-H. Fu, C. Feuillie, S. Derclaye, T.J. Foster, J.A. Geoghegan, Y.F. Dufrêne, Forces between Staphylococcus aureus and human skin, Nanoscale Horiz. 1 (2016) 298-303, http://dx.doi.org/10.1039/C6NH00057F.

[14] C. Formosa, M. Schiavone, A. Boisrame, M.L. Richard, R.E. Duval, E. Dague, Multiparametric imaging of adhesive nanodomains at the surface of Candida albicans by atomic force microscopy, Nanomed. Nanotechnol. Biol. Med. 11 (2015) 57-65, http://dx.doi.org/10.1016/j.nano.2014.07.008.

[15] K.W. Kim, High-resolution imaging of the microbial cell surface, J. Microbiol. 54 (2016) 703-708, http://dx.doi.org/10.1007/s12275-016-6348-5.

[16] P.C. Braga, D. Ricci, Differences in the susceptibility of Streptococcus pyogenes to rokitamycin and erythromycin A revealed by morphostructural atomic force microscopy, J. Antimicrob. Chemother. 50 (2002) 457-460, http://dx.doi. org/10.1093/jac/dkf180.

[17] P.C. Braga, D. Ricci, M. Dal Sasso, Daptomycin morphostructural damage in Bacillus cereus visualized by atomic force microscopy, J. Chemother. Florence Italy 14 (2002) 336-341.

[18] R.L. Soon, R.L. Nation, P.G. Hartley, I. Larson, J. Li, Atomic force microscopy investigation of the morphology and topography of colistin-heteroresistant Acinetobacter baumannii strains as a function of growth phase and in response to colistin treatment, Antimicrob. Agents Chemother. 53 (2009) 4979-4986, http://dx.doi.org/10.1128/AAC.00497-09.

[19] Y.-S. Kim, K.S. Kim, I. Han, M.-H. Kim, M.H. Jung, H.-K. Park, Quantitative and qualitative analysis of the antifungal activity of allicin alone and in combination with antifungal drugs, PLoS One 7 (2012) e38242, http://dx.doi.org/10 1371/journal.pone. 0038242 .

[20] C. Formosa, M. Grare, R.E. Duval, E. Dague, Nanoscale effects of antibiotics on P. aeruginosa, Nanomed. Nanotechnol. Biol. Med. 8 (2012) 12-16, http://dx. doi.org/10.1016/j.nano.2011.09.009.

[21] C. Formosa, M. Schiavone, H. Martin-Yken, J.M. François, R.E. Duval, E. Dague, Nanoscale effects of caspofungin against two yeast species, Saccharomyces cerevisiae and Candida albicans, Antimicrob. Agents Chemother. 57 (2013) 3498-3506, http://dx.doi.org/10.1128/AAC.00105-13.

[22] F. Pillet, C. Formosa-Dague, H. Baaziz, E. Dague, M.-P. Rols, Cell wall as a target for bacteria inactivation by pulsed electric fields, Sci. Rep. 6 (2016) 19778, http://dx.doi.org/10.1038/srep19778.

[23] G.E. Fantner, G. Schitter, J.H. Kindt, T. Ivanov, K. Ivanova, R. Patel, N. Holten-Andersen, J. Adams, P.J. Thurner, I.W. Rangelow, P.K. Hansma, Components for high speed atomic force microscopy, Ultramicroscopy 106 (2006) 881-887, http://dx.doi.org/10.1016/j.ultramic.2006.01.015.

[24] P.K. Hansma, G. Schitter, G.E. Fantner, C. Prater, Applied physics. High-speed atomic force microscopy, Science314 (2006) 601-602, http://dx.doi.org/10. 1126/science.1133497.

[25] T. Ando, N. Kodera, E. Takai, D. Maruyama, K. Saito, A. Toda, A high-speed atomic force microscope for studying biological macromolecules, Proc. Natl. Acad. Sci. U. S. A. 98 (2001) 12468-12472, http://dx.doi.org/10.1073/pnas. 211400898.

[26] Y.F. Dufrêne, T. Ando, R. Garcia, D. Alsteens, D. Martinez-Martin, A. Engel, C. Gerber, D.J. Müller, Imaging modes of atomic force microscopy for application in molecular and cell biology, Nat. Nanotechnol. 12 (2017) 295-307, http:// dx.doi.org/10.1038/nnano.2017.45

[27] N. Kodera, D. Yamamoto, R. Ishikawa, T. Ando, Video imaging of walking myosin V by high-speed atomic force microscopy, Nature468 (2010) 72-76, http://dx.doi.org/10.1038/nature09450.

[28] Y. Sakiyama, A. Mazur, L.E. Kapinos, R.Y.H. Lim, Spatiotemporal dynamics of the nuclear pore complex transport barrier resolved by high-speed atomic force microscopy, Nat. Nanotechnol. 11 (2016) 719-723, http://dx.doi.org/10. 1038/nnano.2016.62.

[29] G.E. Fantner, R.J. Barbero, D.S. Gray, A.M. Belcher, Kinetics of antimicrobial peptide activity measured on individual bacterial cells using high-speed atomic force microscopy, Nat. Nanotechnol. 5 (2010) 280-285, http://dx.doi.org/10. 1038/nnano.2010.29.

[30] H. Watanabe, T. Uchihashi, T. Kobashi, M. Shibata, J. Nishiyama, R. Yasuda, T. Ando, Wide-area scanner for high-speed atomic force microscopy, Rev. Sci. Instrum. 84 (2013) 053702, http://dx.doi.org/10.1063/1.4803449.

[31] T.J. Silhavy, D. Kahne, S. Walker, The bacterial cell envelope, Cold Spring Harb. Perspect. Biol. 2 (2010) a000414, http://dx.doi.org/10.1101/cshperspect. a000414.

[32] G. Francius, O. Domenech, M.P. Mingeot-Leclercq, Y.F. Dufrêne, Direct observation of Staphylococcus aureus cell wall digestion by lysostaphin, J. Bacteriol. 190 (2008) 7904-7909, http://dx.doi.org/10.1128/JB.01116-08.

[33] N.P. Mortensen, J.D. Fowlkes, C.J. Sullivan, D.P. Allison, N.B. Larsen, S. Molin, M.J. Doktycz, Effects of colistin on surface ultrastructure and nanomechanics of Pseudomonas aeruginosa cells, Langmuir 25 (2009) 3728-3733, http: //dx.doi.org/10.1021/la803898g.
[34] A. Gaveau, C. Coetsier, C. Roques, P. Bacchin, E. Dague, C. Causserand, Bacteria transfer by deformation through microfiltration membrane, J. Membr. Sci. 523 (2017) 446-455, http://dx.doi.org/10.1016/j.memsci.2016.10.023.

[35] H. Wang, J.J. Wilksch, T. Lithgow, R.A. Strugnell, M.L. Gee, Nanomechanics measurements of live bacteria reveal a mechanism for bacterial cell protection the polysaccharide capsule in Klebsiella is a responsive polymer hydrogel that adapts to osmotic stress, Soft Matter9 (2013) 7560-7567, http://dx.doi.org/10. 1039/C3SM51325D

[36] C. Formosa, M. Herold, C. Vidaillac, R.E. Duval, E. Dague, Unravelling of a mechanism of resistance to colistin in Klebsiella pneumoniae using atomic force microscopy, J. Antimicrob. Chemother. 70 (2015) 2261-2270, http://dx.doi.org/ $10.1093 / \mathrm{jac} / \mathrm{dkv} 118$

[37] A. Mularski, J. Wilksch, E. Hanssen, J. Li, T. Tomita, S.J. Pidot, T. Stinear, F. Separovic, D. Strugnell, A nanomechanical study of the effects of colistin on the Klebsiella pneumoniae AJ218 capsule, Eur. Biophys. J. EBJ46 (2017) 351-361, http://dx.doi.org/10.1007/s00249-016-1178-2.

[38] M. Tajkarimi, S.H. Harrison, A.M. Hung, J.L. Graves, Mechanobiology of antimicrobial resistant Escherichia coli and Listeria innocua, PLoS One 11 (2016) e0149769, http://dx.doi.org/10.1371/journal.pone.0149769.

[39] Y. Gilbert, M. Deghorain, L. Wang, B. Xu, P.D. Pollheimer, H.J. Gruber, J. Errington, B. Hallet, X. Haulot, C. Verbelen, P. Hols, Y.F. Dufrêne, Single-molecule force spectroscopy and imaging of the vancomycin/d-Ala-d-Ala interaction, Nano Lett. 7 (2007) 796-801, http://dx.doi.org/10.1021/n10700853.

[40] M. Grare, M. Mourer, S. Fontanay, J.-B. Regnouf-de-Vains, C. Finance, R.E. Duval, In vitro activity of para-guanidinoethylcalix[4] arene against susceptible and antibiotic-resistant Gram-negative and Gram-positive bacteria, J. Antimicrob. Chemother. 60 (2007) 575-581, http://dx.doi.org/10.1093/jac/dkm244.

[41] C. Formosa, M. Grare, E. Jauvert, A. Coutable, J.B. Regnouf-de-Vains, M. Mourer, R.E. Duval, E. Dague, Nanoscale analysis of the effects of antibiotics and CX1 on a Pseudomonas aeruginosa multidrug-resistant strain, Sci. Rep. 2 (2012) 575, http://dx.doi.org/10.1038/srep00575.

[42] A. Beaussart, S. El-Kirat-Chatel, R.M.A. Sullan, D. Alsteens, P. Herman, S. Derclaye, Y.F. Dufrêne, Quantifying the forces guiding microbial cell adhesion using single-cell force spectroscopy, Nat. Protoc. 9 (2014) 1049-1055, http://dx. doi.org/10.1038/nprot.2014.066.

[43] J.W. Costerton, P.S. Stewart, E.P. Greenberg, Bacterial biofilms: a common cause of persistent infections, Science284 (1999) 1318-1322.

[44] A. Beaussart, M. Abellán-Flos, S. El-Kirat-Chatel, S.P. Vincent, Y.F. Dufrêne, Force nanoscopy as a versatile platform for quantifying the activity of antiadhesion compounds targeting bacterial pathogens, Nano Lett. 16 (2016) 1299-1307, http://dx.doi.org/10.1021/acs.nanolett.5b04689.

[45] R. Louise Meyer, X. Zhou, L. Tang, A. Arpanaei, P. Kingshott, F. Besenbacher, Immobilisation of living bacteria for AFM imaging under physiological conditions, Ultramicroscopy110 (2010) 1349-1357, http://dx.doi.org/10.1016/j. ultramic.2010.06.010.

[46] P. Tripathi, V. Dupres, A. Beaussart, S. Lebeer, I.J.J. Claes, J. Vanderleyden, Y.F. Dufrêne, Deciphering the nanometer-scale organization and assembly of Lactobacillus rhamnosus GG pili using atomic force microscopy, Langmuir28 (2012) 2211-2216, http://dx.doi.org/10.1021/la203834d.

[47] G. Francius, B. Tesson, E. Dague, V. Martin-Jézéquel, Y.F. Dufrêne, Nanostructure and nanomechanics of live Phaeodactylum tricornutum morphotypes, Environ. Microbiol. 10 (2008) 1344-1356, http://dx.doi.org/10.1111/j. 1462-2920.2007.01551.x.

[48] S. Kasas, A. Ikai, A method for anchoring round shaped cells for atomic force microscope imaging, Biophys. J. 68 (1995) 1678-1680.

[49] C. Formosa, F. Pillet, M. Schiavone, R.E. Duval, L. Ressier, E. Dague, Generation of living cell arrays for atomic force microscopy studies, Nat. Protoc. 10 (2015) 199-204, http://dx.doi.org/10.1038/nprot.2015.004

[50] A. Cerf, J.-C. Cau, C. Vieu, E. Dague, Nanomechanical properties of dead or alive single-patterned bacteria, Langmuir25 (2009) 5731-5736, http://dx.doi. org/10.1021/la9004642.

[51] E. Jauvert, E. Palleau, E. Dague, L. Ressier, Directed assembly of living Pseudomonas aeruginosa bacteria on PEI patterns generated by nanoxerography for statistical AFM bioexperiments, ACS Appl. Mater. Interfaces 6 (2014) 21230-21236, http://dx.doi.org/10.1021/am50624ln

[52] N.B. Arnfinnsdottir, V. Ottesen, R. Lale, M. Sletmoen, The design of simple bacterial microarrays: development towards immobilizing single living bacteria on predefined micro-sized spots on patterned surfaces, PLoS One 10 (2015) e0128162, http://dx.doi.org/10.1371/journal.pone.0128162.

[53] M. Théry, V. Racine, M. Piel, A. Pépin, A. Dimitrov, Y. Chen, J.-B. Sibarita, M. Bornens, Anisotropy of cell adhesive microenvironment governs cell internal organization and orientation of polarity, Proc. Natl. Acad. Sci. U. S. A. 103 (2006) 19771-19776, http://dx.doi.org/10.1073/pnas.0609267103.

[54] A. Rigato, F. Rico, F. Eghiaian, M. Piel, S. Scheuring, Atomic force microscopy mechanical mapping of micropatterned cells shows adhesion geometry-dependent mechanical response on local and global scales, ACS Nano 9 (2015) 5846-5856, http://dx.doi.org/10.1021/acsnano.5b00430. 
[55] J. Tamayo, P.M. Kosaka, J.J. Ruz, Á. San Paulo, M. Calleja, Biosensors based on nanomechanical systems, Chem. Soc. Rev. 42 (2013) 1287-1311, http://dx. doi.org/10.1039/c2cs35293a.

[56] A.E. Pelling, S. Sehati, E.B. Gralla, J.S. Valentine, J.K. Gimzewski, Local nanomechanical motion of the cell wall of Saccharomyces cerevisiae, Science305 (2004) 1147-1150, http://dx.doi.org/10.1126/science.1097640.

[57] G. Longo, L. Alonso-Sarduy, L.M. Rio, A. Bizzini, A. Trampuz, J. Notz, G. Dietler, S. Kasas, Rapid detection of bacterial resistance to antibiotics using AFM cantilevers as nanomechanical sensors, Nat. Nanotechnol. 8 (2013) 522-526, http://dx.doi.org/10.1038/nnano.2013.120.

[58] S. Kasas, F.S. Ruggeri, C. Benadiba, C. Maillard, P. Stupar, H. Tournu, G. Dietler, G. Longo, Detecting nanoscale vibrations as signature of life, Proc. Natl.
Acad. Sci. U. S. A. 112 (2015) 378-381, http://dx.doi.org/10.1073/pnas. 1415348112.

[59] P. Stupar, O. Opota, G. Longo, G. Prod'hom, G. Dietler, G. Greub, S. Kasas, Nanomechanical sensor applied to blood culture pellets: a fast approach to determine the antibiotic susceptibility against agents of bloodstream infections, Clin. Microbiol. Infect. Off. Publ. Eur. Soc. Clin. Microbiol. Infect. Dis. (2017) http://dx.doi.org/10.1016/j.cmi.2016.12.028.

[60] H. Etayash, M.F. Khan, K. Kaur, T. Thundat, Microfluidic cantilever detects bacteria and measures their susceptibility to antibiotics in small confined volumes, Nat. Commun. 7 (2016) 12947, http://dx.doi.org/10.1038/ncomms12947. 